\title{
Symposium: Biologics and Tissue Healing in Orthopaedics
}

\section{Editorial Comment: Symposium: Biologics and Tissue Healing in Orthopaedics}

\author{
Asheesh Bedi MD, Joshua Dines MD
}

The authors certify that they, or any members of their immediate families, have no funding or commercial associations (eg, consultancies, stock ownership, equity interest, patent/licensing arrangements, etc) that might pose a conflict of interest in connection with the submitted article. All ICMJE Conflict of Interest Forms for authors and Clinical Orthopaedics and Related Research ${ }^{\circledR}$ editors and board members are on file with the publication and can be viewed on request.

The opinions expressed are those of the writers, and do not reflect the opinion or policy of $C O R R^{\circledR}$ or the Association of Bone and Joint Surgeons ${ }^{\mathbb{R}}$.

\footnotetext{
A. Bedi MD

MedSport, Department of Orthopaedic Surgery, University of Michigan,

Ann Arbor, MI, USA

J. Dines MD ( $\square)$

Sports Medicine Service, Hospital For Special Surgery, 535 East 70th St,

New York, NY 10021, USA

e-mail: dinesj@hss.edu;

jdinesmd@gmail.com
}

morbidity associated with exposure and soft-tissue dissection. Fixation devices for fracture and soft-tissue repair have likewise improved, with more-rigid implants and pull-out strengths that far exceed typical physiological loads. Advances like these have helped surgeons restore anatomy and function as well as to expedite recovery with reduced morbidity and fewer complications.

Despite these successes, however, the ability of musculoskeletal tissues to heal remains a weak link. The inability to recapitulate the native architecture of the enthesis remains a

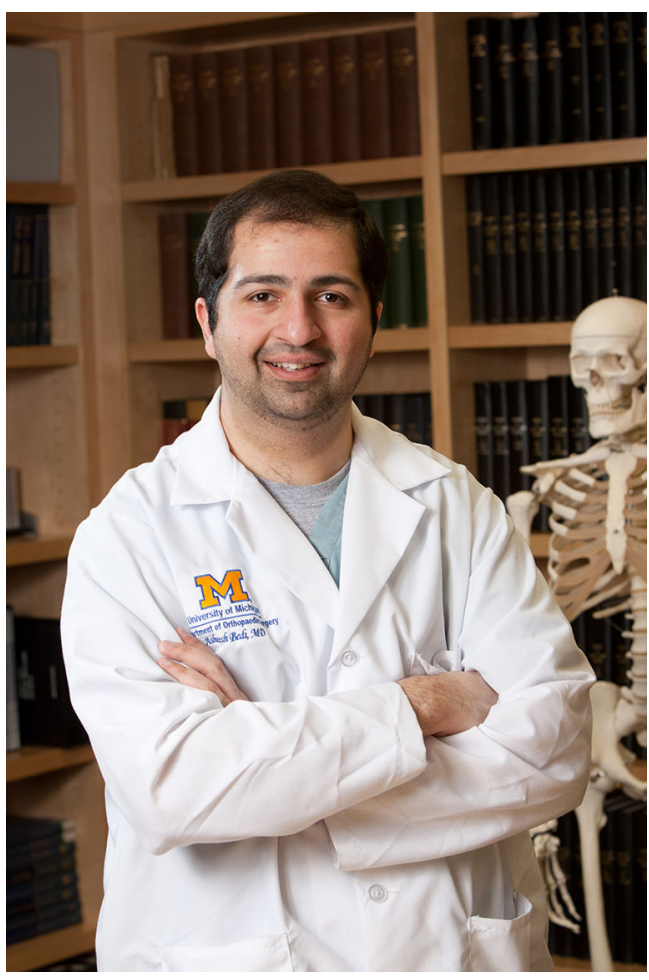

Asheesh Bedi MD 


\section{Symposium: Biologics and Tissue Healing in Orthopaedics}

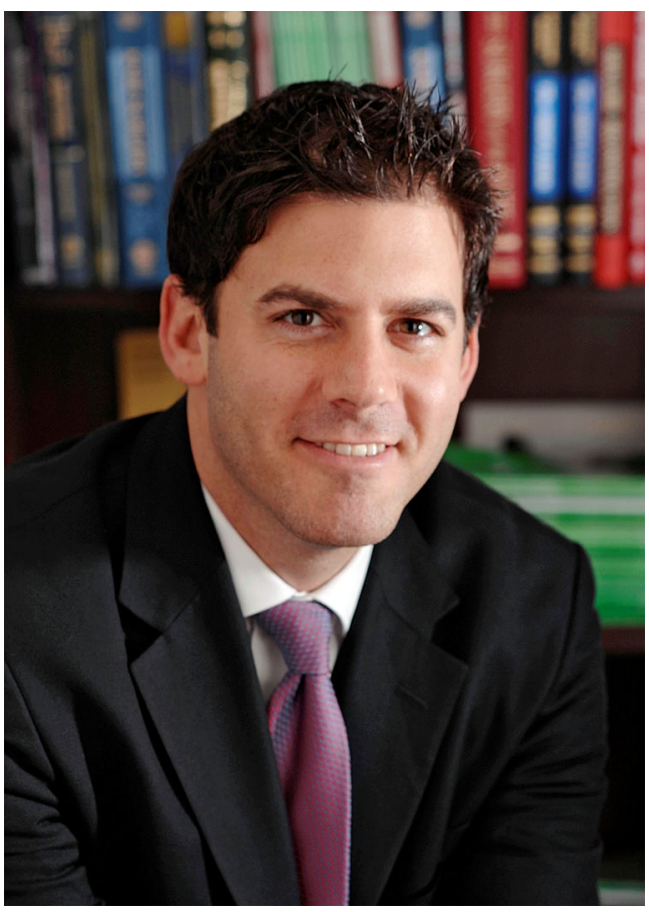

Joshua Dines MD

considerable challenge in ligament reconstruction and rotator cuff repair surgery. This is one of the predominant reasons for structural failure after surgical repair or reconstruction. Joint preservation remains a daunting challenge in spite of improved recognition of focal chondral injury, as our current techniques do not reliably regenerate organized, hyaline cartilage. The next step in musculoskeletal surgery will require an improved understanding of tissue biology in order to develop therapeutic avenues to augment healing.

We are proud to present a series of articles that focuses on biologics and tissue healing in orthopaedics. These studies present important primary research on both growth factor and cell-based strategies to augment healing responses to both injury and surgical repair. The use of biomarkers to help guide decision-making in joint preservation is also reviewed. These considerations will be of paramount importance as we continue to make efforts to improve the quality of our structural and functional outcomes for challenging orthopaedic conditions. We thank the authors who have contributed to this symposium. 